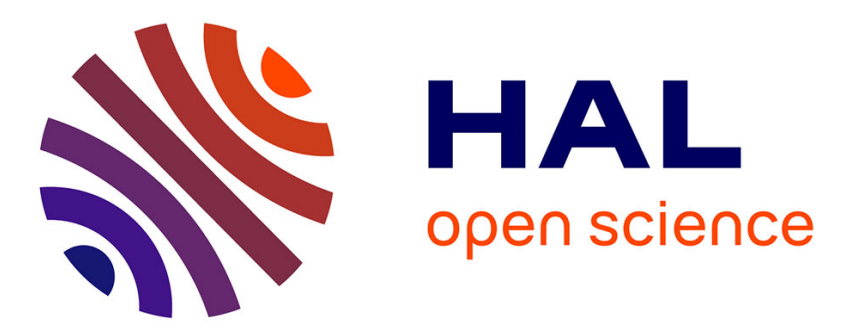

\title{
Application of a front detection photopyroelectric configuration to the study of nonlinear effects in liquid crystals phase transitions
}

\author{
F. Mercuri, M. Marinelli, U. Zammit, R. Pizzoferrato, F. Scudieri
}

\section{- To cite this version:}

F. Mercuri, M. Marinelli, U. Zammit, R. Pizzoferrato, F. Scudieri. Application of a front detection photopyroelectric configuration to the study of nonlinear effects in liquid crystals phase transitions. Journal de Physique IV Proceedings, 1994, 04 (C7), pp.C7-253-C7-256. 10.1051/jp4:1994760 . jpa00253289

\section{HAL Id: jpa-00253289 \\ https://hal.science/jpa-00253289}

Submitted on 1 Jan 1994

HAL is a multi-disciplinary open access archive for the deposit and dissemination of scientific research documents, whether they are published or not. The documents may come from teaching and research institutions in France or abroad, or from public or private research centers.
L'archive ouverte pluridisciplinaire HAL, est destinée au dépôt et à la diffusion de documents scientifiques de niveau recherche, publiés ou non, émanant des établissements d'enseignement et de recherche français ou étrangers, des laboratoires publics ou privés. 


\title{
Application of a front detection photopyroelectric configuration to the study of nonlinear effects in liquid crystals phase transitions
}

\author{
F. Mercuri, M. Marinelli, U. Zammit, R. Pizzoferrato and F. Scudieri \\ Dipartimento di Ingegneria Meccanica - II, Università di Roma "Tor Vergata", Via della Ricerca Scientifica, \\ 00133 Roma, Italy
}

\begin{abstract}
The aim of this paper is to present an experimental configuration which enables the use of the pyroelectric transducer in the front detection configuration. This configuration has been applied to the study of thermal parameters in the vicinity of two phase transitions of $9 \mathrm{CB}$ liquid crystal. Anomalies have been found in the phase of the photopyroelectric signal near the phase transitions. Strong nonlinear effects have been detected both in the $2 \omega$ signal amplitude and phase.
\end{abstract}

\section{INTRODUCTION}

Photothermal techniques can be roughly divided in Back and Front Detection Techniques (BDT and FDT). In FDT the heat produced in the sample on one side via modulated electromagnetic radiation is detected on the same side by a transducer. In BDT the transducer probes the opposite side with respect to the heated one [1]. Some of the photothermal techniques such as gas-microphone and photodefletion may be used in FDT and BDT. Piezoelectric and pyroelectric transducer configurations, on the other hand, have been mainly used as BDT. The depth resolution of a technique depends on the thermal diffusion length. This means that such a depth resolution can be increased by increasing the modulation frequency $f$. The maximum value of $f$ that can be used depends on the detection configuration and on the energy input. With a given input the high frequency limit is lower in BDT than in FDT due to the sample that acts as a low pass filter.

In this paper the FDT pyroelectric configuration has been used to study liquid crystal phase transitions at different frequencies.

\section{EXPERIMENTAL}

Fig. 1 shows a sketch of the sample cell. A $300 \mu \mathrm{m}$ thick $\mathrm{LiTaO}_{3}$ transducer with a transparent ITO electrode on one side and an opaque one on the opposite side. The acoustooptically modulated laser light passes through the transparent electrode and is absorbed by the opaque one which is in contact with the liquid crystal sample. The sample temperature is changed with a temperature rate change of about 20 $\mathrm{mK} / \mathrm{min}$. The signal from the detector is analysed by means of a two channel lock-in amplifier operating in current mode. In this configuration $n$ attenuation from the detection electronic is expected up to a frequency of $70 \mathrm{KHz}$. 


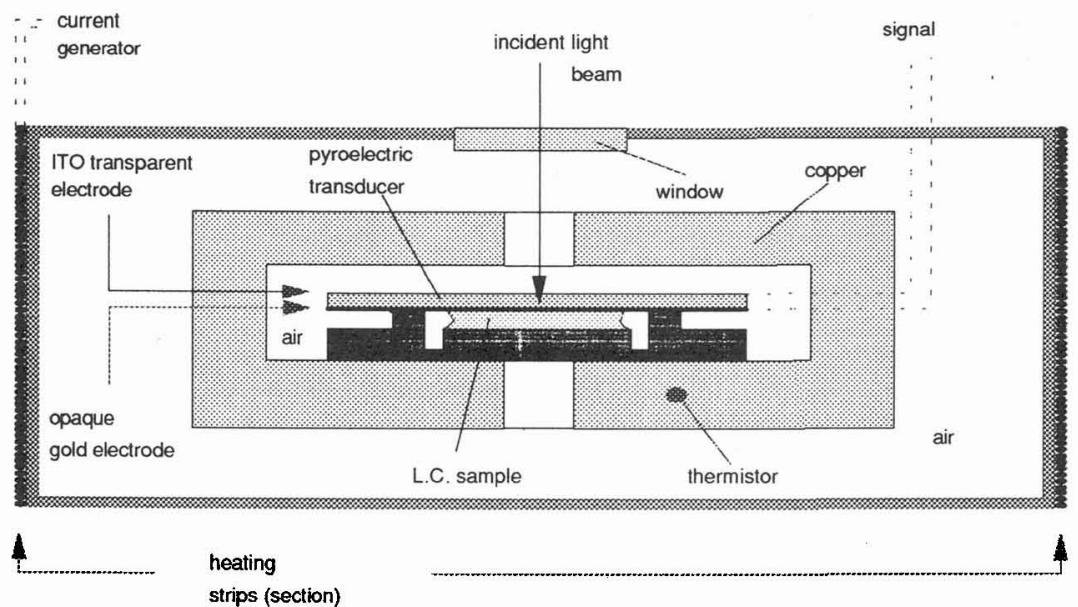

Fig. 1: Sample holder.

\section{SAMPLE}

The 9CB sample belongs to the series of the $\mathrm{nCB}$ (n-cynobiphenyl) liquid crystals [2]. It has a crystalline (K) phase below $41^{\circ} \mathrm{C}$ and a isotropic (I) phase over $50^{\circ} \mathrm{C}$. Between these temperatures it shows two mesophases: a smectic-A $\left(S_{A}\right)$ and a nematic $(N)$ ones below and over $47.8^{\circ} \mathrm{C}$ respectively. The $\mathrm{K}-\mathrm{S}_{\mathrm{A}}$ phase transition is a first order one.The $\mathrm{S}_{\mathrm{A}}-\mathrm{N}$ and the $\mathrm{N}-\mathrm{I}$ are second and weakly first order phase transitions respectively and are included in the temperature range of investigation.

\section{RESULTS}

Fig. 2 shows the amplitude and phase behaviour as a function of temperature at different frequencies, the liquid crystal sample being thermally thick in all cases. The amplitude measurements as a function of frequency seem to show no significant change.

\section{Phase $\left(^{\circ}\right)$}

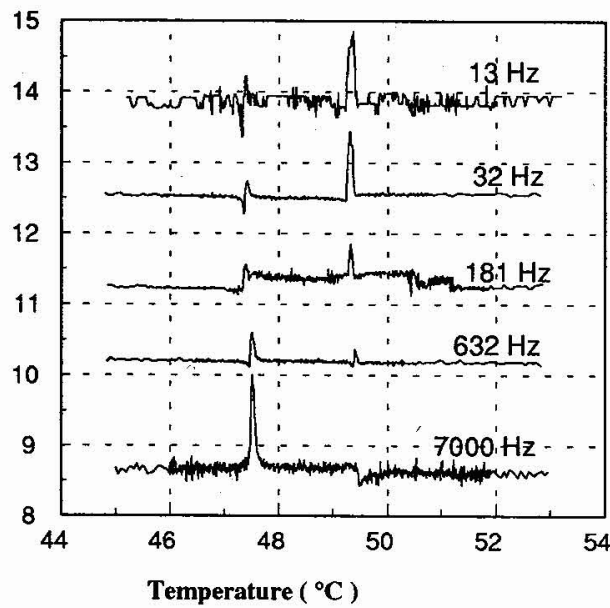

Amplitude ( a. u. )

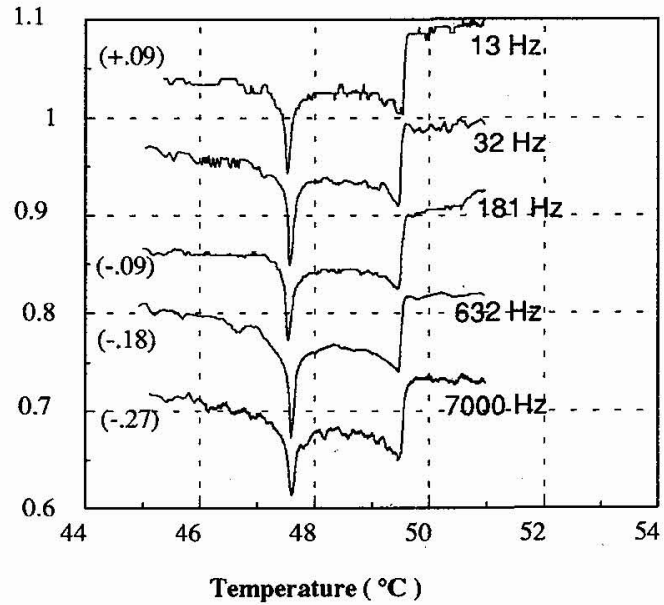

Fig. 2: Phase and amplitude vs. temperature at different frequencies. The amplitude signals are shifted by the amounts reported in the graphs. 
Anomalies on the other hand were found in the phase near the two transitions. In the case of the second order phase transition a "bipolar" behaviour is evident at low frequencies and a peak appears at high frequency.

The situation is reversed in the case of the first order one which shows a peak at low frequency and a "bipolar" behaviour at high frequency. It should be noted that this phase change at the transitions cannot be explained by the standard RG theory for which, being the sample optically opaque and thermally thick, the phase must remain constant. This is true also in the transition region where the sample thermal diffusivity is expected to decrease. The phase changes are, on the other hand, very small and they can be detected because of the very low noise which the photopyroelectric configuration allows. Different mechanisms can be responsible for this phase change close to the transition temperature. Liquid crystal molecules are thermally anisotropic and they can align in given direction close to the sample surface. This alignment can introduce inhomogeneities in the sample thermal properties, the sample having for example a different thermal diffusivity with respect to the bulk. In this case the sample is no longer homogeneous and the phase can be sensitive to variations of thermal parameters. We have also to consider the possibility of a thermal resistance at the interface due to a bad thermal contact. Also in this case, depending on the thermal resistance, the phase can be sensitive to the thermal parameters variation. It could also be possible that nonlinear effects in the heat transport process arise in the vicinity of the phase transition because of the strong temperature dependence of the thermal parameters close to $\mathrm{T}_{\mathrm{c}}$.
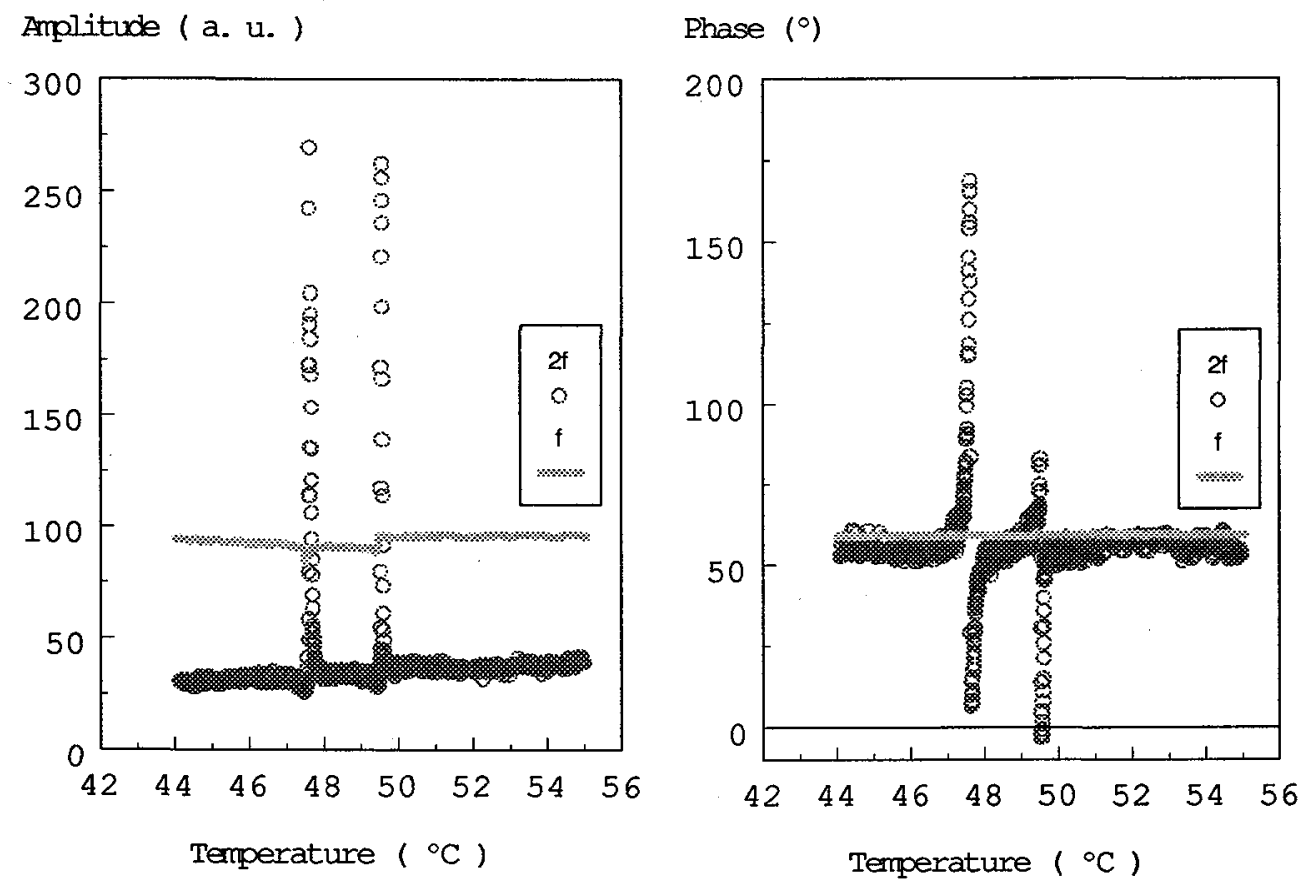

Fig. 3: Amplitude and phase vs. temperature at $2 \omega$ and at the fundamental frequencies.

Fig. 3 shows the $2 \omega$ amplitude and phase obtained at $32 \mathrm{~Hz}$ compared with the corresponding measurements at the fundamental frequency [3]. Huge variations are evident close to the transition temperature both in the amplitude and phase. This results however cannot rule out the possibility that the phase variation at the fundamental frequency are due to the sample thermal inohmogeneity or to the thermal resistance between the sample and the transducer. It could be possible, on the other hand that such a strong 
nonlinearity, affect the signal at the fundamental frequency, thus explaining the anomalies observed at the fundamental frequency. These are very preliminar results and experiments are in progress. In particular we are now studying aligned liquid crystal layers in which the effect of the thermal inohmogeneity is suppressed.

\section{References}

[1]. Marinelli M., Zammit U., Mercuri F., Pizzoferrato R., J. Appl. Phys. 72 (3), 1096-1100 (1992)

[2]. Zammit U., Marinelli M., Pizzoferrato R., Scudieri F., Martellucci S., Phys. Rev. A 41, 1153-1155 (1990)

[3]. Korpiun P., Weiser J., Photoacoustic and Photothermal Phenomena III, Springer Series in Optical Sciences, 69, 634-636 (1992) 